Э. Ф. Шарипова. Практико-ориентированные задания по технологии как условие формирования функциональной грамотности

Научная статья

УДК 371.3

DOI: $10.18101 / 2307-3330-2021-3-87-91$

\title{
ПРАКТИКО-ОРИЕНТИРОВАННЫЕ ЗАДАНИЯ ПО ТЕХНОЛОГИИ КАК УСЛОВИЕ ФОРМИРОВАНИЯ ФУНКЦИОНАЛЬНОЙ ГРАМОТНОСТИ
}

\author{
(C) Шарипова Эльвира Фоатовна \\ кандидат педагогических наук, доцент, \\ Южноуральский государственный гуманитарно-педагогический университет \\ Россия, 454080, г. Челябинск, пр. Ленина, 69 \\ sharipovaef@cspu.ru
}

\begin{abstract}
Аннотация. В статье рассматривается проблема разработки практикоориентированных заданий по технологии в контексте формирования функциональной грамотности. На основе анализа содержания понятия «функциональная грамотность» обосновывается целесообразность применения заданий, предполагающих контекстуальное использование полученных ранее знаний. Представлена схема интеллектуальных действий учащегося по решению практико-ориентированных задач, включающая восприятие текста с учетом контекста, выбор стратегии и ее апробацию. На основе данного алгоритма разработана структура заданий, включающая первичные целевые установки, собственно текст и контекст, заданный либо условиями самого задания, либо через дополнительные материалы, предоставляемые ученику. В статье также представлен ряд примеров заданий, разработанных согласно этому алгоритму, и общие рекомендации по составлению аналогичных заданий.

Ключевые слова: технология, практико-ориентированные задания, функциональная грамотность.
\end{abstract}

\section{Для цитирования}

Шарипова Э. Ф. Практико-ориентированные задания по технологии как условие формирования функциональной грамотности // Вестник Бурятского государственного университета. Образование. Личность. Общество. 2021. № 3. С. 87-91.

Международная программа для оценки образовательных достижений учащихся PISA все более широко применяется. Специфика подхода в рамках программы PISA заключается в том, что, во-первых, акцент делается прежде всего на применение универсальных умений и навыков, во-вторых, проверяется готовность применять не навык вообще, а комплекс различных навыков с учетом конкретной ситуации ${ }^{1}$. На первый план выходят не знания и умения, а понимание. При этом актуализация универсальных знаний, умений и навыков осуществляется на конкретном предметном содержании. Этот подход, на наш взгляд, хорошо согласуется с целями и задачами предметной области «Технология», поэтому те методики, которые применяются для формирования функциональной грамотно-

1 PISA 2018 GlobalCompetenceFramework // OECDinstance. 2020. URL: https://www.oecd-ilibrary.org/sites/043fc3b0en/index.html?itemId=/content/component/043fc3b0-en (дата обращения: 14.09.2020). 
сти, могут быть использованы на уроках технологии при условии адекватного содержательного наполнения.

Основным инструментом как проверки, так и формирования функциональной грамотности являются практико-ориентированные задачи, содержание которых приближено к реальной жизни (ситуационные задачи, кейсы). Сегодня существует не так много подобных заданий, поэтому учителю часто приходится самому их разрабатывать. Для того чтобы это было проще сделать, важен желаемый алгоритм действий учащегося

Можно представить схему интеллектуальных действий учащегося по решению задачи в виде следующего алгоритма:

1. Восприятие и понимание текста. Понятие «текст» предполагает в этом случае очень широкое толкование. Это не только письменный источник, это любые знаково-символические информационные системы разнообразного происхождения и предназначения [1].

Текст характеризуется следующими признаками:

1. Имеет символически знаковую структуру

2. Служит источником информации

В учебном процессе ситуации реального мира так или иначе воспринимаются учеником через посредничество формального языка: текста задания, пояснение учителя и пр. Если же речь идет о непосредственном взаимодействии с реальной ситуацией, то и здесь процесс решения проблемы запускается после «текстуализации» - учащийся должен сформулировать, вербализировать проблему. Поэтому здесь и далее мы будем использовать термин «текст» для обозначения того стимульного материала (задания, ситуации и пр.), который содержит в себе информацию о проблеме и запускает процесс ее решения.

Ключевой момент функциональной грамотности - понимание, а для этого необходимо, чтобы учащийся не только мог воспринять и интерпретировать знаковую структуру текста (умел читать, понимал значение слов, мог прочитать чертеж или схему и пр.), но и учитывал контекст, в котором существует данный текст. В широком значении контекст - это среда, в которой существует объект. Например, задача подбора материалов для отделки квартиры может отличаться по некоторым нюансам в зависимости от того, предполагается ли, что ремонт выполняют сами собственники или речь идет о наемной бригаде. Алгоритм разработки и изготовления швейного изделия может отличаться в зависимости от того, будет ли изделие единичным или планируется отшить несколько единиц изделия и пр.

2. Следующий этап - выбор стратегии. На этом этапе происходит уточнение целей (при необходимости), формулировка задач и выбор методов их достижения. В числе таких действий могут быть применение готового алгоритма (алгоритмов), поиск недостающей информации, сопоставление информации, оценка достоверности и пр., проведение опыта, выполнение практических действий и пр. Задача учащегося - либо свести ситуацию к готовым алгоритмам, которые ему известны, либо определить шаги, необходимые для выполнения этого действия, в том числе направленные на освоение новых алгоритмов. 
Э. Ф. Шарипова. Практико-ориентированные задания по технологии как условие формирования функциональной грамотности

3. Выполнение необходимых действий. На этом этапе происходит реализация стратегии, выбранной на предыдущем этапе.

4. Анализ и интерпретация полученных результатов. Необходимо оценить, удалось ли достичь цели. Если ответ отрицательный, алгоритм может быть повторен.

Фактически перед нами частный случай процесса решения проблемы, основное внимание в котором уделено процессу понимания ситуации и выбору алгоритмов для его решения. Процессуальное ядро функциональной грамотности умение распознать типовые компоненты в конкретном контексте и применить имеющиеся знания, в том числе и для восполнения недостающей информации. Исходя из этого можно предположить, что ключевым звеном методики формирования функциональной грамотности должны стать образовательные ситуации, включающие предварительные цели, обозначенные либо учителем, либо представленные в самом стимульном материале, текст (в широком значении этого слова) и контекст его презентации.

По определению В. В. Серикова, «ситуация - это особый педагогический механизм, который ставит воспитанника в новые условия, трансформирующие привычный ход его жизнедеятельности» [2]. Применительно к ситуациям, направленным на формирование функциональной грамотности, мы предлагаем следующую структуру:

1. Целевая установка. Она может быть полной или требовать уточнения, формулироваться самим педагогом или совместно с учащимися. По сути, это то задание, которое учащийся получает на старте.

2. «Текст». Под «текстом» мы понимаем весь стимульный материал, который предоставляется учащемуся: текстовый, графический, материальный и т. д. Текст может быть представлен в формате гипертекста, как, например, в кейс-заданиях, где для решения задачи необходимо работать с системой документов.

3. Контекст. Представляет те условия, которые могут или должны влиять на принятие решения учащимся, но не представлены в тексте в явном виде. Например, если мы решаем изобретательскую задачу «Разработка автоматической системы полива», то в контексте личной проблемы мы решаем ее для малого объема (цветочного горшка) и учитываем, что система должна быть бесшумной и компактной. Та же задача в контексте приусадебного хозяйства приобретает совсем другие параметры.

В образовательном процессе презентация образовательной ситуации может осуществляться через проблемные вопросы в рамках эвристической беседы, задания, ситуационные задачи, кейсы, а также в формате исследовательских и проектных работ. При этом следует учесть, что в образовании мы чаще всего имеем дело именно с презентацией проблемы: ребенок знакомится с явлением, ситуацией с подачи педагога, и деление на «текст» и «контекст» происходит извне. В реальной жизни мы чаще имеем дело с манифестацией - проявлением чеголибо в поле зрения субъекта. В данном случае деление на «текст» и «контекст» осуществляется субъектом самостоятельно. На наш взгляд, формирование функциональной грамотности будет тем эффективнее, чем ближе удастся подойти к 
реальным условиям решения проблемы. Рассмотрим пример: учащиеся разобрали технологию приготовления винегрета и им предстоит приступить к его приготовлению. Мы можем предложить учащимся список необходимых продуктов и инструментов а также определить, чего не хватает, или перейти в кухонную зону, где уже подготовлены продукты и инструменты, и предложить приступить к готовке, не уточняя, что не все необходимые компоненты присутствуют, предоставив учащимся самим это обнаружить.

Для разработки практико-ориентированного задания можно предложить ответить на следующие вопросы:

Что формируем (проверяем)? На этом этапе мы решаем, какие знания и умения, прежде всего предметные, мы будем включать в задание.

В каких жизненных ситуациях могут быть актуализированы данные знания и умения? При выборе ситуаций необходимо убедиться, что сама ситуация может быть понята учеником. В идеале ситуация должна опираться на имеющийся у него жизненный опыт или описывать ситуации, которые детям легко представить.

Как включить ситуацию в образовательный контекст? Какие вспомогательные материалы предоставить? Здесь можно выделить несколько вариантов:

1. Непосредственное включение в ситуацию. По сути, это практическое задание, опирающееся на реальные условия жизни учеников. Сюда можно отнести задания типа «Посчитать семейный бюджет для собственной семьи» или определить стратегию сбора средств для покупки чего-либо, составить план закупок и меню для классного чаепития. В таких заданиях целесообразно четко обозначать условия, но при этом источники информации максимально приблизить к реальным. Например, при разработке меню чаепития можно предложить учащимся самим договориться о сумме на покупки, выбрать магазины, которыми они планируют воспользоваться, определиться с вкусовыми предпочтениями. Вспомогательными материалами могут быть наводящие вопросы, направленные на то, чтобы учащиеся глубже проанализировали ситуацию: заказать продукты с доставкой или самовывозом; покупать готовые блюда или купить продукты и приготовить самим; взять более дешевый продукт или при выборе руководствоваться анализом состава. Чем больше контекстов смогут разглядеть и учесть в задании учащиеся, тем лучше.

Гипотетическое включение в ситуацию. В этом случае учащимся предлагается представить себя в ситуации, которая с ними не происходила, но могла бы возникнуть. Например, представьте, что вы собираетесь на каникулы в Москву на поезде. Продумайте свой рацион на время дороги.

2. Конкретная ситуация с абстрактными персонажами. В этом случае в описываемой ситуации уже есть участники, попавшие в некоторое затруднительное положение, проблемы которых нам предстоит решить. Такие задания хороши тем, что позволяют моделировать самые разные ситуации, в том числе из сферы профессиональной деятельности, а также, при желании, работать над коммуникативными навыками (развивать навык понимания мотивов и поступков других людей). 
Э. Ф. Шарипова. Практико-ориентированные задания по технологии как условие формирования функциональной грамотности

Одну и ту же ситуацию можно использовать в нескольких заданиях. Также можно варьировать сложность заданий, меняя условия и объем информации. Ситуации, которые могут стать основой для задания, можно предлагать формулировать самим учащимся, брать из фильмов или мультфильмов, информационных передач, литературных произведений. Такого рода задания можно использовать в том числе для работы в период дистанционного обучения. Можно предположить, что включение задач такого типа в практику преподавания технологии позволит не только более эффективно формировать функциональную грамотность, но и будет способствовать достижению метапредметных результатов

Литература

1. Кузнецов В. Г. Текст и специфика гуманитарных наук // Философия науки и техники. 2020. № 2. URL: https://cyberleninka.ru/article/n/tekst-i-spetsifika-gumanitarnyh-nauk (дата обращения: 14.05.2021). Текст: электронный.

2. Сериков В. В. Образование и личность. Теория и практика проектирования педагогических систем. Москва: Логос, 1999. 272 с. Текст: непосредственный.

Статья поступила в редакциию 18.11.2021; одобрена после рецензирования 22.11.2021; принята к публикации 07.12.2021.

\section{PRACTICE-ORIENTED TASKS ON TECHNOLOGY CLASS AS A CONDITION FOR THE FORMATION OF FUNCTIONAL LITERACY}

\section{Elvira F. Sharipova}

Candidate of Pedagogical Sciences, Associate Professor

South Ural State University of Humanities and Pedagogy

69 Lenin Ave., Chelyabinsk, 454080, Russia

sharipovaef@cspu.ru

The article examines the problem of developing practical tasks on technology class in the context of the formation of functional literacy. Based on the analysis of the content of the concept of «functional literacy», the expediency of using tasks that involve the contextual application of previously acquired knowledge is substantiated. The scheme of the student's intellectual actions in solving practical problems is presented, including the perception of the text taking into account the context, the choice of a strategy and its approbation. On the basis of this algorithm, a structure of tasks has been developed, which includes primary target settings, the text itself and the context specified either by the conditions of the task itself, or through additional materials provided to the student. The article also presents a number of examples of tasks developed according to this algorithm and general recommendations for compiling similar tasks.

Keywords: Technology, practice-oriented tasks, functional literacy.

The article was submitted 18.11.2021; approved after reviewing 22.11.2021; accepted for publication 07.12.2021. 